\title{
Percutaneous Liver Fiducial Implants: Techniques, Materials and Complications
}

\author{
David Roberge and Tatiana Cabrera \\ McGill University Health Centre, \\ Canada
}

\section{Introduction}

Stereotactic body radiation therapy (SBRT) is a radiotherapy technique that utilizes precise targeting to deliver high doses of tumoricidal radiation in the course of a small number of treatment sessions. SBRT is used to treat a variety of primary and metastatic tumours of the lung, liver, pancreas, kidney, spine and prostate. These treatments are already standard for medically inoperable early lung cancer and indications are evolving for other disease sites.

In SBRT of liver lesions (Dawood et al., 2009; Lo et al., 2010), tumour-targeting accuracy is crucial given the radiosensitive nature of the liver, frequent proximity of the tumour to the small bowel and significant movement of the liver with breathing. Reduction of normal tissue irradiation requires the radiation to be image-guided (as opposed to relying on skin marks or body casts). This image-guidance is typically accomplished through visualization of a surrogate to the tumour. The surrogate can be the whole liver, the diaphragm or an implanted marker (Wunderink et al., 2010).

Implanted markers have the advantage of being visible on planar $\mathrm{x}$-ray images and fluoroscopy loops. If large enough, they can also be seen on images produced with the treatment beam. The details of the implementation of fiducial imaging vary with different radiotherapy devices but typically images of the fiducials are correlated to the position of the chest wall at different points in the breathing cycles. This gives the user knowledge of the displacement of the tumour (assumed to be at a fixed distance from the fiducials). One can then choose to turn on the beam in a specific phase of the breathing cycle or have the radiation delivery device track the movement of the tumour.

As an example, the Cyberknife system acquires up to 15 pairs of stereoscopic x-rays just before treatment. Fiducials are automatically detected by the system's image analysis software. The 3D position of the fiducials is then correlated to the position of chest wall as recorded by the movement of 3 lights on the patient's chest. The robot on which the radiation source is mounted can then use the model correlating chest wall motion and fiducial motion to mimic the movement of the tumour while the patient breathes (Figure 1). In this process, there is continuous monitoring (via cameras) of the chest wall but only intermittently imaging of the fiducials with stereoscopic $x$-rays. These additional $x$-rays are used to verify and update the correlation model. 


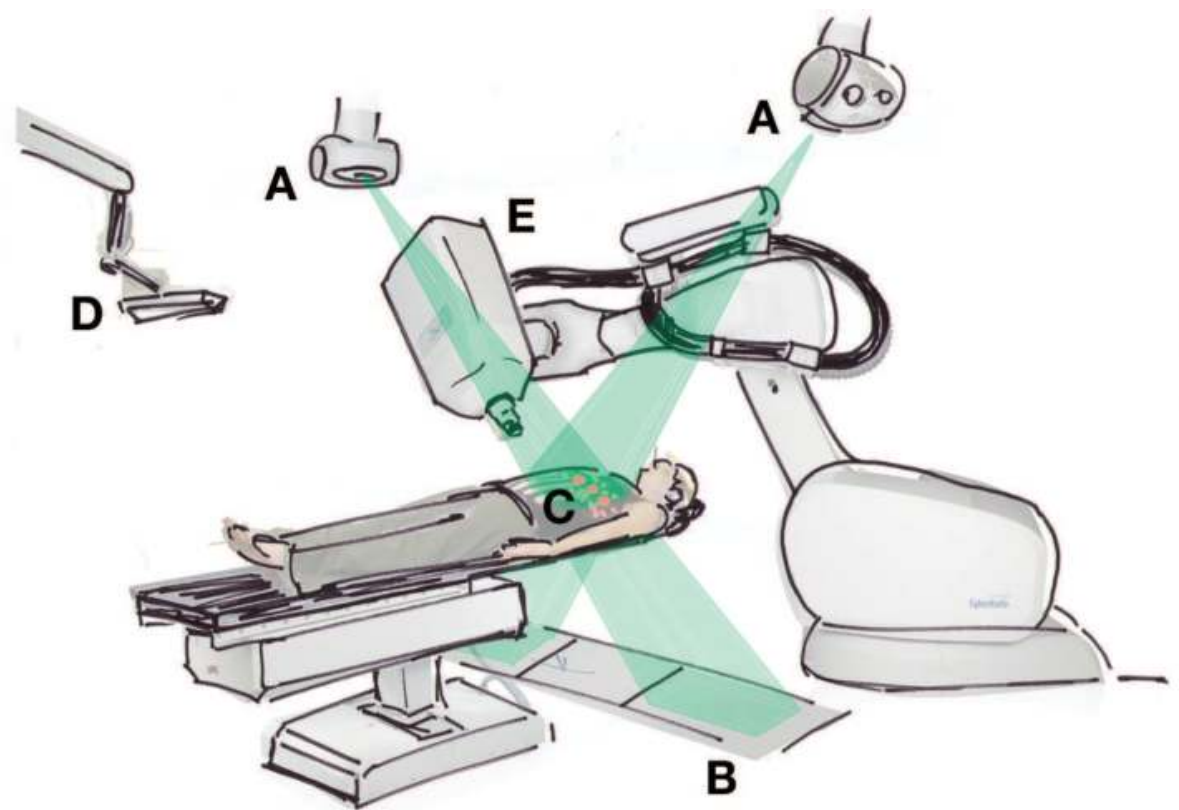

Fig. 1. Cyberknife radiosurgery device. X-ray tubes (A) are used to produce stereoscopic images recorded digitally (B) and correlated to the movement of lights on the patient's chest (C) which are monitored by two cameras (D). The model correlating the position of the chest wall to the position of the fiducials seen on the $\mathrm{x}$-ray images is used to guide the miniature linear accelerator at the head of the robot $(\mathrm{E})$.

\section{Percutaneous fiducial implantation technique}

Fiducials are inserted using image-guidance (Sotiropoulou et al., 2010). Before the procedure, appropriate laboratory parameters are obtained and reviewed within an acceptable time frame, these include a complete blood count and prothrombin time with international normalized ratio. Patients with previously documented abnormalities in laboratory tests may require these to be repeated closer to the time of the procedure. Platelet transfusions are considered for platelet levels of less than 60,000/mL. Antiplatelet medications should be discontinued 7 days before the fiducial implantation; warfarin is generally discontinued 5 days before insertion, and heparin and related products discontinued 12-24 hrs prior to the procedure. Barring complications, these treatments can be restarted 24-48 hours following the procedure.

Imaging of the target lesion is reviewed with the radiation oncologist. This enables proper planning of the procedure, selection of the appropriate equipment (depending if a biopsy is required or not) and lesion(s) (it is possible that only selected lesions will be targeted for radiotherapy, and therefore for fiducial implantation).

The fiducial insertion is typically performed on an outpatient basis. The choice of imaging modality will depend on availability and operator preference. Most radiologists are comfortable with ultrasound or CT guidance. Although each modality has its advantages, certain situations may require a specific type of imaging. Typically CT is preferred for 
fiducial insertion. Most patients are poor candidates for ultrasound-guided procedure because of body habitus, previous liver surgery and/or the presence of multiple lesions. CT also allows a pre-implant scan that can be acquired with contrast. This allows a better mapping of the target lesion and its neighbouring vascular structures, hopefully resulting in better fiducial placement with reduced risk of migration. This CT can also be used for treatment planning if the fiducials subsequently cause significant artefact.

Needle selection is based on the type of fiducial to be use, the number of fiducials to be placed and if a biopsy is required or not. A coaxial 19G needle is useful to perform a smallgauge core biopsy (18G), have enough tissue for histological analysis, and also allows for placement of our cylindrical gold fiducials.

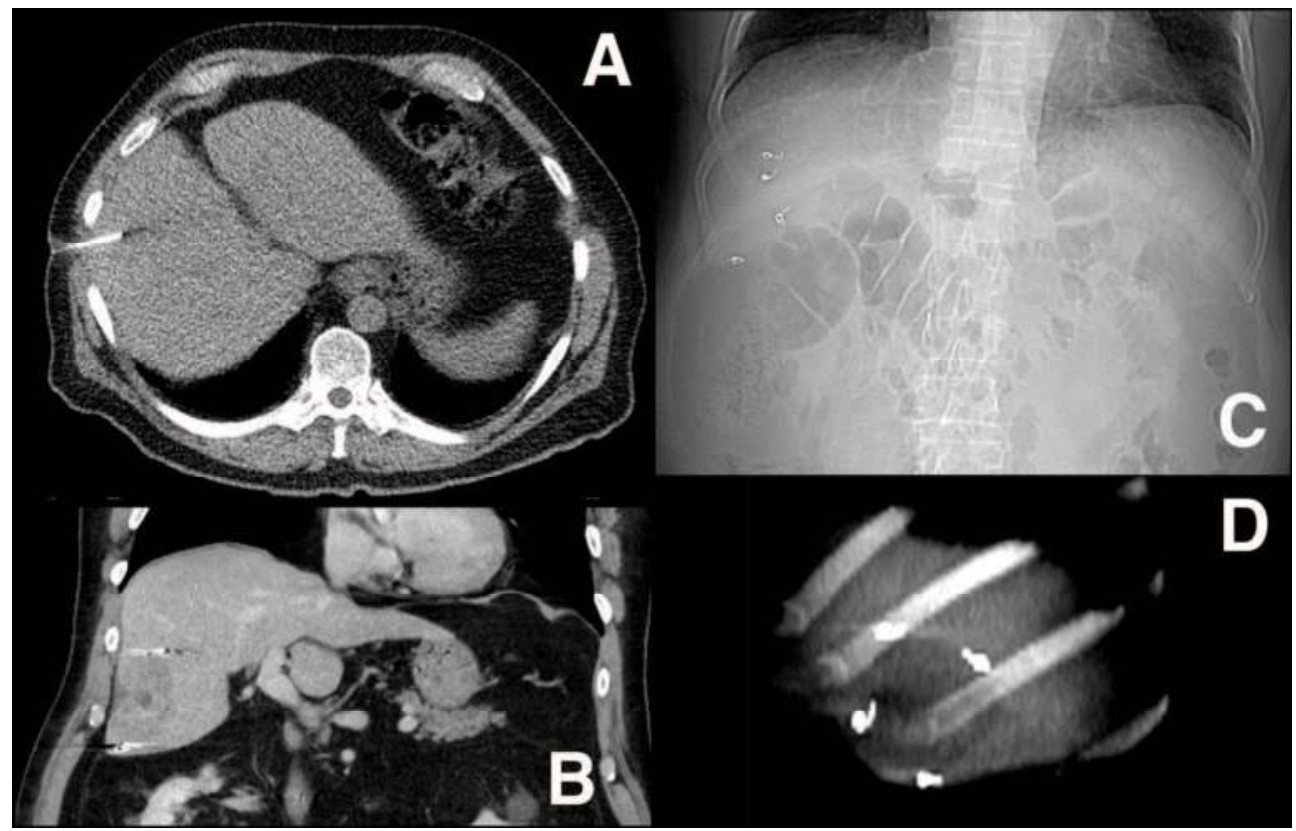

Fig. 2. A) A $22 \mathrm{G}$ needle is placed with a low radiation dose CT scan to place a Nester platinum coil. This case has a $6 \mathrm{~cm}$ lesion and 4 coils were placed at different levels (B, C, D).

With current radiotherapy systems, treatment can - if necessary - proceed with a single marker. The disadvantages of using a single marker are that movement of the marker within the liver will be difficult to detect and rotation of the target will not be reflected by the position of the marker. Geometrically, a minimum of 3 markers are required to assess rotations (as long as the fiducials are not all in a straight line). Extra markers also allow detection of migration (a constant relationship between the markers will reflect stability in their position). When there are too many markers or they are too close together (the Cyberknife system, as an example, suggests a minimum spacing of $2 \mathrm{~cm}$ ) this may lead to confusion at the time of treatment. The markers need not be within the lesion, as long as they will move in synchrony with the tumour. For example, markers can be implanted below a lesion high under the dome of the diaphragm in order to avoid the risk of pneumothorax. For small lesions, two markers placed at different sites but through the same 
puncture may be sufficient; however, for bigger lesions, 3-4 markers may be preferred and the procedure may require multiple punctures.

At the end of the implant, a final scout imaging will confirm intra-hepatic fiducial placement.

\subsection{Types of fiducial markers}

Fiducials are typically made of a biologically inert metal with a high atomic number. These can be designed specifically for radiotherapy, repurposed devices or simple non-commercial materials. Several issues will be considered in choosing a marker. These include price, convenience, availability as well as the specific imaging system used for radiotherapy guidance.

Modern radiotherapy equipment will most often be purchased with an integrated kilovoltage imaging source dedicated to image-guidance. These systems should be able to easily resolve small gold markers with a diameter of $0.5 \mathrm{~mm}$ (or less) but will be influenced by body habitus and overlying structures. To be visible with a megavoltage radiotherapy beam, markers will need to be thicker (this may mean $0.75-1.1 \mathrm{~mm}$ diameter for gold) or longer (in the case of a marker which will coil up into a dense mass as it exits the needle). Images thus obtained as the treatment beam traverses the patient can be an excellent quality assurance tool.

\begin{tabular}{|c|c|c|c|c|c|}
\hline Type of fiducial & Material & Diameter & Shape & $\begin{array}{l}\text { Needle } \\
\text { gauge }\end{array}$ & Provider \\
\hline \multicolumn{6}{|l|}{$\begin{array}{l}\text { Plain / Non- } \\
\text { commercial }\end{array}$} \\
\hline Spheres & Gold & $2.0 \mathrm{~mm}$ & spherical & $\geq 12$ ga & varied \\
\hline Cylinder / wire & Gold & varied & cylindrical & varied & varied \\
\hline \multicolumn{6}{|l|}{ Repurposed } \\
\hline $\begin{array}{l}\text { Embolization } \\
\text { coils }\end{array}$ & Platinum & 0.889 & loose coil & 22 ga & Cook Medical \\
\hline \multicolumn{6}{|l|}{ Commercial } \\
\hline Visicoil $^{\mathrm{TM}}$ & Gold & $0.35-1.1 \mathrm{~mm}$ & tight linear coil & 17-19 ga & Core Oncology \\
\hline $\begin{array}{l}\text { Best Gold } \\
\text { Markers }\end{array}$ & Gold & $0.8-1.2 \mathrm{~mm}$ & $\begin{array}{c}\text { cylindrical, available with } \\
\text { absorbable spacer }\end{array}$ & 17-18 ga & Best Medical \\
\hline $\begin{array}{c}\text { Cybermark }^{\mathrm{TM}} / \\
\text { Align }^{\mathrm{TM}}\end{array}$ & Gold & $0.8-1.2 \mathrm{~mm}$ & Knurled solid cylinder & 17-18 ga & $\begin{array}{l}\text { Civco medical } \\
\text { solutions }\end{array}$ \\
\hline Coupled ${ }^{\mathrm{TM}}$ & Gold & $0.8-1 \mathrm{~mm}$ & $\begin{array}{l}\text { two } 3 \mathrm{~mm} \text { cylinders with } \\
\text { absorbable spacer }\end{array}$ & 17-18 ga & $\begin{array}{l}\text { Civco medical } \\
\text { solutions }\end{array}$ \\
\hline FlexiMarc $^{\mathrm{TM}}$ & Gold & $0-9-1.2 \mathrm{~mm}$ & $\begin{array}{c}\text { gold nodes along thin gold } \\
\text { wire }\end{array}$ & 17-18 ga & $\begin{array}{l}\text { Civco medical } \\
\text { solutions }\end{array}$ \\
\hline FlexiCoil $^{\mathrm{TM}}$ & Gold & $0-9-1.2 \mathrm{~mm}$ & tight coil with solid ends & 17-18 ga & $\begin{array}{l}\text { Civco medical } \\
\text { solutions }\end{array}$ \\
\hline $\begin{array}{l}\text { X-Mark }{ }^{\mathrm{TM}} / \mathrm{X}- \\
\text { Mark Ultra }^{\mathrm{TM}}\end{array}$ & Gold & $\begin{array}{c}0.85- \\
1.15 \mathrm{~mm}\end{array}$ & $\begin{array}{l}\text { multiple short bands along } \\
\text { gold wire }\end{array}$ & 17-18 ga & $\begin{array}{l}\text { IZI Medical } \\
\text { Products }\end{array}$ \\
\hline Gold AnchorTM & Gold & $0.28 \mathrm{~mm}$ & bendable notched wire & $22-25 \mathrm{ga}$ & $\begin{array}{c}\text { Naslund } \\
\text { Medical AB } \\
\text { / Radiadyne }\end{array}$ \\
\hline AnchorMarke® & Gold & $\mathrm{n} / \mathrm{a}$ & $\begin{array}{l}\text { cylinder encapsulated in } \\
\text { bioabsorbable polymer }\end{array}$ & $\mathrm{n} / \mathrm{a}$ & BrachySciences \\
\hline BeamMarks ${ }^{\circledR}$ & $\begin{array}{c}\text { Nickel } \\
\text { titanium }\end{array}$ & $1-1.2 \mathrm{~mm}$ & extruded star shape & $\mathrm{n} / \mathrm{a}$ & Beampoint \\
\hline
\end{tabular}

Table 1. Radiotherapy fiducials 
The simplest markers are sterile sections of gold wire or gold spheres. Repurposed markers can include embolization coils designed for intravascular use. We have had good experience with these platinum coils as they can be placed with fine needles, are stable in the liver and are easily visualized with radiotherapy imaging. A disadvantage of these coils is that they can sometimes fail to bunch up into a tight mass - when this happens, they don't offer as precise a reference as a small solid piece of gold. Dedicated markers tend to have been designed to increase convenience and limit migration. Markers can thus be provided preloaded in needles or carriers. The markers can have an irregular surface or a bendable structure to "hook" into the liver. Tissue absorbable material between markers can be used to preserve marker spacing and reduce migration within the needle track. A common commercial radiotherapy fiducial (Visicoil, Core Oncology, Santa Barbara, CA) has a linear shape. As these markers can be $2-3 \mathrm{~cm}$ long, both ends of a single marker may be informative in resolving possible target rotation.

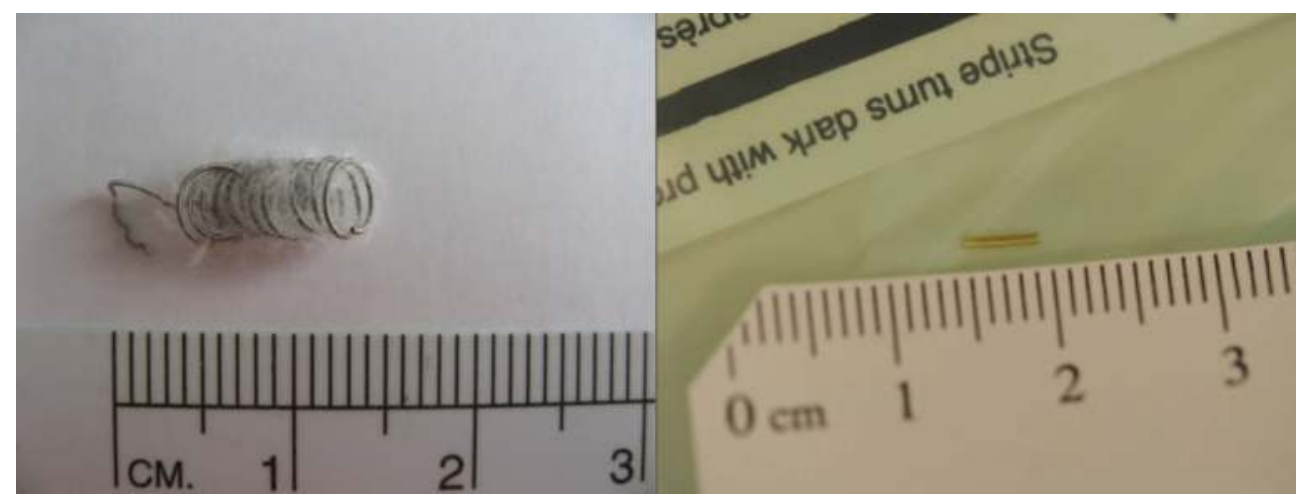

Fig. 3. Examples of a repurposed (platinum embolization coil on the left) and noncommercial (section of gold wire on the right) fiducial

\section{Risks of percutaneous fiducial implantation}

Fiducial placement is the source of several inconveniences. It leads to a delay in treatment even when appointments are readily available, many clinicians will impose up to a one week delay from fiducial placement to treatment planning in order to allow the markers to "settle". The procedure is associated with additional costs and the fiducials can create significant imaging artefacts on CT. In addition, the percuteneous procedure has a variety of risks. Minor complications have been reported in $17.3 \%$ and major complications in $5 \%$ of cases (Kothary et al., 2009). There are generic risks that come with introducing any needle into the liver: pain, pneumothorax, hemothorax, perforation of non target organs (the gallbladder being the most common), bile peritonitis, infection, hemobilia, neuralgia and tumour seeding. For most of these events, the biopsy literature serves as a basis of a risk estimate. Specific to fiducial placement is the risk of migration of the marker.

\subsection{Pain}

Pain is the most common complication on any percutaneous procedure. Up to $84 \%$ of patients will have at least mild discomfort. When present, pain can usually be managed 
with small amounts of narcotics (Cardella et al., 2003). Is important to recognize and evaluate any moderate to severe pain, which could be related with bleeding, gallbladder or biliary puncture. When pain is severe enough to require hospitalization, radiological evaluation is warranted

\subsection{Fiducial migration}

Fiducial migration is a twofold problem, first because of the risk of tumour mistargeting if unrecognized migration occurs within the organ of interest, and second because of potential toxicity from the marker escaping through the hepatic veins.

\subsubsection{Gross fiducial migration}

Fiducials and radioactive seeds are commonly placed in the prostate. There is ample literature describing migration of these to the lung (without any serious consequence). In placing gold markers for pulmonary radiation, migration into the pleural cavity, pulmonary veins or bronchial tree will sporadically occur. For the liver, the available literature is more limited, with hepatic veins representing the potential route of fiducial migration (no cases of biliary tree migration have been reported).

In a series of 21 patients implanted with $2 \mathrm{~mm}$ gold spheres, one of the fiducials migrated through the inferior vena cava to a small vein at the hip where it remained lodged without apparent clinical consequence (Shirato et al., 2003). In a series from Stanford University Medical Center, 33 patients underwent CT-guided placement of $0.8 \mathrm{~mm}$ by $5 \mathrm{~mm}$ hepatic fiducials. In these cases there was no gross marker migration and one patient experienced a small hemorrhagic pleural effusion (Kothary et al., 2009).

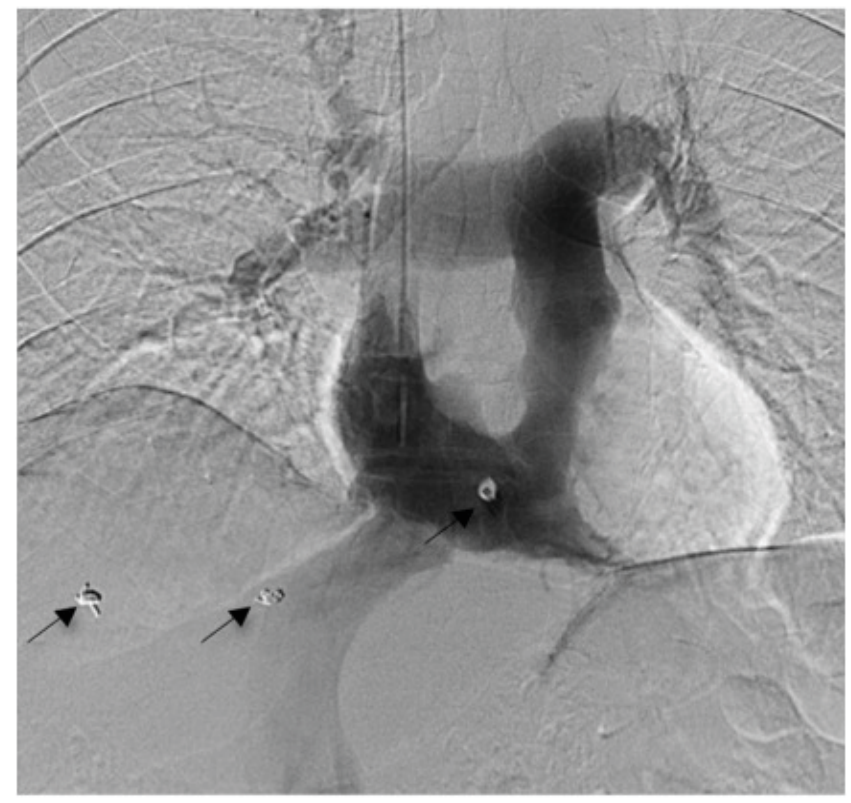

Fig. 4. Platinum coil lodged at the junction of the inferior vena cava and right atrium after migration from the liver. 
In our own experience, we had a case of cardiac migration of a liver fiducial (Hennessey et al., 2009). This occurred in an 81 year old patient planned for SBRT in the context of oligometastatic gastric cancer. For image-guidance, Nester embolization coils (Cook Medical Inc., Bloomington, Indiana) were planned to be implanted under CT guidance. Prior to the placement of each coil the location of the tip of the delivery needle was confirmed by CT imaging. During the procedure, the third coil unexpectedly migrated through the hepatic vein to the inferior vena cava and lodged at the vena cava/right atrial junction. The patient remained asymptomatic. He was immediately referred to angiography for extraction of the coil. Using fluoroscopic guidance, an EN Snare Retrieval System (Hatch Medical L.L.C., Snellville, GA, USA) was introduced through a jugular catheter, successfully grasped the coil and was removed. The patient was kept overnight for observation and no immediate or delayed complications were encountered due to the migration or retrieval of the coil. $\mathrm{He}$ subsequently went on to be treated using the remaining fiducials

\subsubsection{Intra-hepatic fiducial migration}

Migration of fiducials within the targeted organ has been described. Most published work concerns prostate radiotherapy with studies looking at the relative position of 3-4 prostate markers as a surrogate to migration (Sommerkamp et al., 1988). In limited experience with hepatic fiducials, intra-organ migration appears minimal - in the order of $2-3 \mathrm{~mm}$ (Sommerkamp et al., 1988; Kitamura et al., 2002). However, quantification of movement within the liver is limited by the frequent lack of precise landmarks within this large, deformable organ. To deal with this issue, clinicians have relied on treatment margins, repeated 3D imaging and/or implantation of redundant fiducials.

\subsection{Bleeding}

The most important complication of liver puncture is bleeding, that can be severe when it occurs intraperitoneally. The clinical signs include changes in vital signs, imaging evidence of intraperitoneal bleeding, and subcutaneous hematoma. In this case, the patient requires hospitalization with possible transfusion, radiological intervention or surgery. Such bleeding has been estimated to occur in between 1:25,000 to 1:10,000 procedures after an intercostal percutaneous approach. Severe bleeding is evident within 2-4 hrs, but late haemorrhage can occur even up to one week after the procedure. Less severe bleeding, defined as that sufficient to cause pain or decreased blood pressure / tachycardia, but not requiring transfusion or intervention, occurs in approximately 1 in 500 procedures (Cardella et al., 2003; Seeff et al., 2010).

Non-symptomatic bleeding, detectable by ultrasonography may occur in $20 \%$ of patients.

\subsection{Pneumothorax}

Pneumothorax is critical to recognize immediately after the procedure, because it can lead to immediate catastrophic outcomes. This is the most frequent complication after lung implantation, although only $14 \%$ of these require a chest tube to resolve (Sotiropoulou et al., 2010). Pneumothorax is less frequent on liver fiducal placements. An advantage of CT guidance is the easy diagnosis of pneumothorax with immediate treatment.

\subsection{Tumour seeding}

Although there are no reports of malignant seeding after fiducial placement, it is possible that this can occur at a similar rate than for other percutaneous diagnostic and therapeutic 
procedures in patients with HCC. For example, in a meta-analysis the median risk of seeding was $2.3 \%$ for the biopsy group and less than $1 \%$ for RFA with or without biopsy (Stigliano et al., 2007).

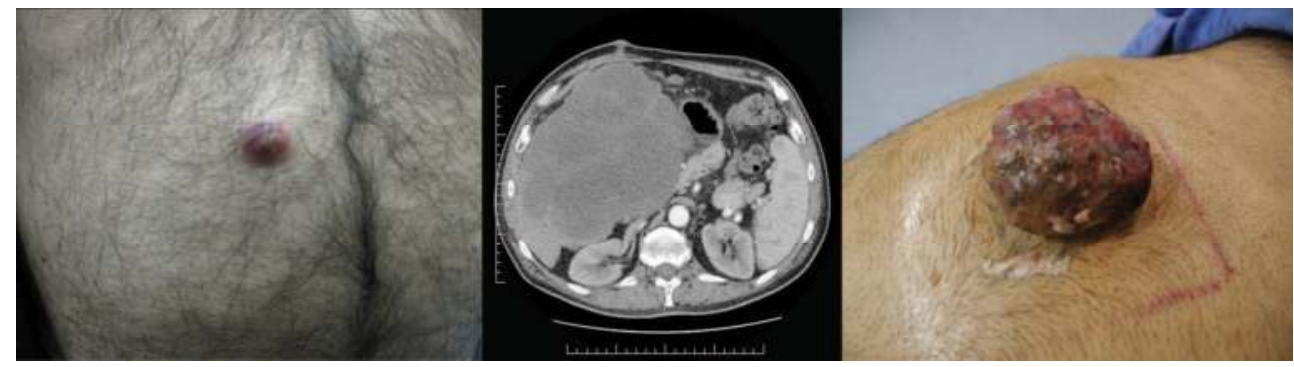

Fig. 5. Tumour seeding following percutaneous biopsy

\section{Alternatives to percutaneous fiducial implantation}

Fiducials are for now often a necessary evil. As radiotherapy image-guidance develops, the use of fiducials will likely decrease. This will happen faster in the lung, where the tumours can be more easily visualized on $2 \mathrm{D}$ and non-contrast 3D imaging. Alternatives to percutaneous fiducial placement have developed in the chest mainly in an attempt to reduce the risk of pneumothorax. In the abdomen, the need for alternatives has not been as strongly felt without common serious complications.

\subsection{Endoscopic ultrasound (EUS) fiducial placement}

Endoscopic ultrasound (EUS), has the advantage of proximity to structures of the mediastinum and retroperitoneum that are otherwise not easily accessible by percutaneous approaches (Varadarajulu et al., 2010). Initially, the EUS technique required the use of a 19G FNA needle to deliver the fiducial, but because of the size and stiffness of the needle, the accurate placement of fiducials was compromised. The introduction of new smaller fiducial markers that can fit on a $22 \mathrm{G}$ needle now allows optimal placement in a variety of locations. It is minimally invasive and allows easy access to structures around the GI track. More frequently suggested for pancreatic lesions, it may also be used for retroperitoneal lymph nodes, the left adrenal gland, and the left hepatic lobe, including the caudate. The fiducials are liberated through the stomach or duodenum, commonly with prophylactic antibiotics (Ammar et al., 2010; DiMaio et al., 2010).

Reported success rates of EUS-guided fiducial placement are 85 to $100 \%$ with minimal complications and no migration. Failure to place a fiducial in the desired location was due to either anatomic considerations or limitations of the equipment when a $19 \mathrm{G}$ needle was used. The technical success using a $22 \mathrm{G}$ needle is reported at $97 \%$ because this type of needle does not produce the same endoscope rigidity as the $19 \mathrm{G}$ needle.

Despite these reports, the use of EUS for liver fiducial placement remains anecdotal and restricted to the left lobe.

\subsection{Non fiducial based image-guidance}

Modern radiotherapy devices often have the capability to acquire volumetric imaging at the time of treatment. These "cone-beam" CT scans typically take 30-60 seconds to acquire and 
thus suffer from breathing artefacts. As the technology advances, it is becoming possible to sort the images acquired during a rotation into phases of a $4 \mathrm{D} \mathrm{CT}$ scan. It is also possible, in some cases, to use multiple breath holds to acquire a 3D image at a fixed point in the respiratory cycle. The volumetric image is then used to position the patient for treatment (Case et al., 2009). Because the tumour will typically not be visible, the entire liver will be used as a surrogate. Although they avoid fiducial placement, these techniques have the disadvantage of not allowing monitoring of the tumour position during treatment.

\subsection{Endovascular fiducial placement}

In specific situations such as severe ascites, a known or suspected hemostatic defect or morbid obesity, patients can undergo intrahepatic artery coils implant. The Nester type coils (Cook, Inc; Bloomington, IN) may have a special role because its platinum structure that is radiopaque and easy to visualize during the radiotherapy. They can be liberated with a 0.035 inch catheter; microcatheters can also be used for a more selective coil placement. When possible, two or three different tumour vessels should be embolized and the most distal position possible. The intra-arterial coil placement has the benefit of low risk of migration, and the proximity with the target lesion; it has the disadvantage of blocking an artery that could be used for further chemoembolisation.

Intravenous fiducial placement is described for lung tumour. There are no cases, to our knowledge, of this type of procedures for liver lesions, which could have a high risk of migration.

\section{Conclusion}

Interventional radiologist and radiation oncologist often collaborate in the implantation of radio-opaque markers for the targeting of focused radiation. Although this percutaneous fiducials placement is a useful and generally safe procedure, it carries a variety of small risks of which radiologists, radiation oncologists and patients should be aware.

\section{References}

Ammar, T.; Cote, G.A.; Creach, K.M.; Kohlmeier, C.; Parikh, P.J. \& Azar, R.R. (2010). Fiducial placement for stereotactic radiation by using EUS: feasibility when using a marker compatible with a standard 22-gauge needle. Gastrointest Endosc, Vol. 71, No. 3, (Mar 2010), pp. 630-633, 1097-6779

Cardella, J.F.; Bakal, C.W.; Bertino, R.E.; Burke, D.R.; Drooz, A.; Haskal, Z., et al. (2003). Quality improvement guidelines for image-guided percutaneous biopsy in adults. J Vasc Interv Radiol, Vol. 14, No. 9 Pt 2, (Sep 2003), pp. S227-230, 1051-0443

Case, R.B.; Sonke, J.J.; Moseley, D.J.; Kim, J.; Brock, K.K. \& Dawson, L.A. (2009). Inter- and intrafraction variability in liver position in non-breath-hold stereotactic body radiotherapy. Int J Radiat Oncol Biol Phys, Vol. 75, No. 1, (Sep 1 2009), pp. 302-308, 1879-355X

Dawood, O.; Mahadevan, A. \& Goodman, K.A. (2009). Stereotactic body radiation therapy for liver metastases. Eur J Cancer, Vol. 45, No. 17, (Nov 2009), pp. 2947-2959, 18790852

DiMaio, C.J.; Nagula, S.; Goodman, K.A.; Ho, A.Y.; Markowitz, A.J.; Schattner, M.A. \& Gerdes, H. (2010). EUS-guided fiducial placement for image-guided radiation 
therapy in GI malignancies by using a 22-gauge needle (with videos). Gastrointest Endosc, Vol. 71, No. 7, (Jun 2010), pp. 1204-1210, 1097-6779

Hennessey, H.; Valenti, D.; Cabrera, T.; Panet-Raymond, V. \& Roberge, D. (2009). Cardiac embolization of an implanted fiducial marker for hepatic stereotactic body radiotherapy: a case report. J Med Case Reports, Vol. 3, No. 2009), pp. 140, 1752-1947

Kitamura, K.; Shirato, H.; Shimizu, S.; Shinohara, N.; Harabayashi, T.; Shimizu, T., et al. (2002). Registration accuracy and possible migration of internal fiducial gold marker implanted in prostate and liver treated with real-time tumor-tracking radiation therapy (RTRT). Radiother Oncol, Vol. 62, No. 3, (Mar 2002), pp. 275-281, 0167-8140

Kothary, N.; Heit, J.J.; Louie, J.D.; Kuo, W.T.; Loo, B.W., Jr.; Koong, A., et al. (2009). Safety and efficacy of percutaneous fiducial marker implantation for image-guided radiation therapy. J Vasc Interv Radiol, Vol. 20, No. 2, (Feb 2009), pp. 235-239, 15357732

Lo, S.S.; Dawson, L.A.; Kim, E.Y.; Mayr, N.A.; Wang, J.Z.; Huang, Z. \& Cardenes, H.R. (2010). Stereotactic body radiation therapy for hepatocellular carcinoma. Discov Med, Vol. 9, No. 48, (May 2010), pp. 404-410, 1944-7930

Seeff, L.B.; Everson, G.T.; Morgan, T.R.; Curto, T.M.; Lee, W.M.; Ghany, M.G., et al. (2010). Complication rate of percutaneous liver biopsies among persons with advanced chronic liver disease in the HALT-C trial. Clin Gastroenterol Hepatol, Vol. 8, No. 10, (Oct 2010), pp. 877-883, 1542-7714

Shirato, H.; Harada, T.; Harabayashi, T.; Hida, K.; Endo, H.; Kitamura, K., et al. (2003). Feasibility of insertion/implantation of 2.0-mm-diameter gold internal fiducial markers for precise setup and real-time tumor tracking in radiotherapy. Int J Radiat Oncol Biol Phys, Vol. 56, No. 1, (May 1 2003), pp. 240-247, 0360-3016

Sotiropoulou, E.; Stathochristopoulou, I.; Stathopoulos, K.; Verigos, K.; Salvaras, N. \& Thanos, L. (2010). CT-guided fiducial placement for cyberknife stereotactic radiosurgery: an initial experience. Cardiovasc Intervent Radiol, Vol. 33, No. 3, (Jun 2010), pp. 586-589, 1432-086X

Stigliano, R.; Marelli, L.; Yu, D.; Davies, N.; Patch, D. \& Burroughs, A.K. (2007). Seeding following percutaneous diagnostic and therapeutic approaches for hepatocellular carcinoma. What is the risk and the outcome? Seeding risk for percutaneous approach of HCC. Cancer Treat Rev, Vol. 33, No. 5, (Aug 2007), pp. 437-447, 03057372

Sommerkamp, H.; Rupprecht, M. \& Wannenmacher, M. (1988). Seed loss in interstitial radiotherapy of prostatic carcinoma with I-125. Int J Radiat Oncol Biol Phys, Vol. 14, No. 2, (Feb 1988), pp. 389-392, 0360-3016

Varadarajulu, S.; Trevino, J.M.; Shen, S. \& Jacob, R. (2010). The use of endoscopic ultrasound-guided gold markers in image-guided radiation therapy of pancreatic cancers: a case series. Endoscopy, Vol. 42, No. 5, (May 2010), pp. 423-425, 1438-8812

Wunderink, W.; Mendez Romero, A.; Seppenwoolde, Y.; de Boer, H.; Levendag, P. \& Heijmen, B. (2010). Potentials and limitations of guiding liver stereotactic body radiation therapy set-up on liver-implanted fiducial markers. Int J Radiat Oncol Biol Phys, Vol. 77, No. 5, (Aug 1 2010), pp. 1573-1583, 1879-355X 


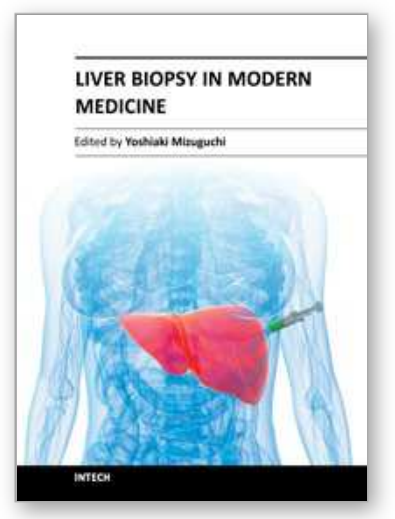

\author{
Liver Biopsy in Modern Medicine \\ Edited by Dr. Yoshiaki Mizuguchi
}

ISBN 978-953-307-883-0

Hard cover, 378 pages

Publisher InTech

Published online 10, October, 2011

Published in print edition October, 2011

Liver biopsy, first performed by Paul Ehrlich in 1883, remains an important diagnostic procedure for the management of hepatobiliary disorders and the candidate/donated organ for transplantation. The book "Liver biopsy in Modern Medicine" comprises 21 chapters covering the various aspects of the biopsy procedure in detail and provides an up-to-date insightful coverage to the recent advances in the management of the various disorders with liver biospy. This book will keep up with cutting edge understanding of liver biopsy to many clinicians, physicians, scientists, pharmaceutics, engineers and other experts in a wide variety of different disciplines.

\title{
How to reference
}

In order to correctly reference this scholarly work, feel free to copy and paste the following:

David Roberge and Tatiana Cabrera (2011). Percutaneous Liver Fiducial Implants: Techniques, Materials and Complications, Liver Biopsy in Modern Medicine, Dr. Yoshiaki Mizuguchi (Ed.), ISBN: 978-953-307-883-0, InTech, Available from: http://www.intechopen.com/books/liver-biopsy-in-modern-medicine/percutaneous-liverfiducial-implants-techniques-materials-and-complications

\section{INTECH}

open science | open minds

\section{InTech Europe}

University Campus STeP Ri Slavka Krautzeka 83/A 51000 Rijeka, Croatia Phone: +385 (51) 770447

Fax: +385 (51) 686166 www.intechopen.com

\section{InTech China}

Unit 405, Office Block, Hotel Equatorial Shanghai No.65, Yan An Road (West), Shanghai, 200040, China 中国上海市延安西路65号上海国际贵都大饭店办公楼 405 单元 Phone: +86-21-62489820

Fax: $+86-21-62489821$ 
(C) 2011 The Author(s). Licensee IntechOpen. This is an open access article distributed under the terms of the Creative Commons Attribution 3.0 License, which permits unrestricted use, distribution, and reproduction in any medium, provided the original work is properly cited. 